\title{
Blockade of muscarinic receptors impairs the retrieval of well-trained memory
}

\author{
Shogo Soma ${ }^{1}$, Naofumi Suematsu ${ }^{2}$ and Satoshi Shimegi ${ }^{1,2 *}$ \\ ${ }^{1}$ Department of Health and Sport Sciences, Graduate School of Medicine, Osaka University, Osaka, Japan \\ ${ }^{2}$ Department of Health and Sport Sciences, Graduate School of Frontier Biosciences, Osaka University, Osaka, Japan
}

\section{Edited by:}

Fernanda Laezza, University of Texas Medical Branch, USA

\section{Reviewed by:}

Dafin F. Muresanu, University of Medicine and Pharmacy 'Iuliu Hatieganu', Romania Fernanda Laezza, University of Texas Medical Branch, USA

\section{*Correspondence:}

Satoshi Shimegi, Department of Health and Sport Sciences,

Graduate School of Medicine, Osaka University, 1-17 Machikaneyama,

Toyonaka, Osaka, 560-0043, Japan e-mail:shimegi@

vision.hss.osaka-u.ac.jp
Acetylcholine (ACh) is known to play an important role in memory functions, and its deficit has been proposed to cause the cognitive decline associated with advanced age and Alzheimer's disease (the cholinergic hypothesis). Although many studies have tested the cholinergic hypothesis for recently acquired memory, only a few have investigated the role of $\mathrm{ACh}$ in the retrieval process of well-trained cognitive memory, which describes the memory established from repetition and daily routine. To examine this point, we trained rats to perform a two-alternative forced-choice visual detection task. Each trial was started by having the rats pull upward a central-lever, which triggered the presentation of a visual stimulus to the right or left side of the display monitor, and then pulling upward a stimulus-relevant choice-lever located on both sides. Rats learned the task within 10 days, and the task training was continued for a month. Task performance was measured with or without systemic administration of a muscarinic ACh receptor (mAChR) antagonist, scopolamine (SCOP), prior to the test. After 30 min of SCOP administration, rats stopped manipulating any lever even though they explored the lever and surrounding environment, suggesting a loss of the task-related associative memory. Three hours later, rats were recovered to complete the trial, but the rats selected the levers irrespective of the visual stimulus, suggesting they remembered a series of lever-manipulations in association with a reward, but not association between the reward and visual stimulation. Furthermore, an m1-AChR, but not nicotinic AChR antagonist caused a similar deficit in the task execution. SCOP neither interfered with locomotor activity nor drinking behavior, while it influenced anxiety. These results suggest that the activation of mAChRs at basal ACh levels is essential for the recall of well-trained cognitive memory.

Keywords: acetylcholine, dicyclomine, muscarinic $\mathrm{m} 1$ receptor, the cholinergic hypothesis, retrieval, well-trained cognitive memory, Long-Evans rat

\section{INTRODUCTION}

A loss of cholinergic function in the central nervous system has been demonstrated to contribute significantly to the cognitive decline associated with advanced age and Alzheimer's disease (AD; reviewed, Bartus, 2000). This hypothetical causality is known as "the cholinergic hypothesis," which was initially presented over 30 years ago (Bartus et al., 1982). Brains from patients of old age or AD-related cognitive dysfunction have consistently shown damage or abnormalities in cholinergic pathways that appeared to correlate well with the level of cognitive decline (Whitehouse et al., 1981, 1982). This hypothesis has since served as the basis for the majority of treatment strategies and drug development approaches for AD to date. Thus, acetylcholine (ACh) is now firmly entrenched as a key factor to prevent and cure the disease, although the etiology still remains to be less understood.

The typical symptom pattern of $\mathrm{AD}$ begins with memory loss, especially for recent events (short-term or working memory). With AD progression, at least one other cognitive deficit occurs, including apraxia, agnosia, or a disturbance in executive functioning. Symptoms of AD eventually include impairment of well-learned functions expressed frequently and almost automatically in daily living. For example, apraxia is defined as a higher-order motor disturbance of goal-directed behavior characterized by an inability to perform previously learned movements in the absence of weakness or sensory defects (Edwards et al., 1991). Agnosia is defined as an inability to recognize objects that are familiar or well-known (Bennett, 2000; Abe et al., 2007).

Previous studies testing the cholinergic hypothesis have mostly focused on functions relevant to recently acquired memory (Zarrindast et al., 1996; Marti Barros et al., 2004; Soares et al., 2006; Piri and Zarrindast, 2011). Those studies demonstrated that subclasses of ACh receptors (AChRs) involved in memory retrieval depended on the memory type. For example, pretest administration of a muscarinic AChR (mAChR) antagonist impaired the retrieval of memory acquired from contextual fear conditioning (Soares et al., 2006). On the other hand, nicotinic AChRs (nAChRs) contributed to memory retrieval in the inhibitory avoidance task (Zarrindast et al., 1996; Marti Barros et al., 2004; Piri and Zarrindast, 2011). To date, however, it still remains unclear about the relationship between the cholinergic system and memory established by daily routine. The purpose 
of this study was to examine whether the cholinergic hypothesis explains deficits of well-learned memory retrieval.

To examine the role of ACh in well-learned memory functions, we applied a two-alternative forced-choice (2AFC) visual detection task to rats as a test of memory function, because this task requires multiply-associative learning. Here, rats were required to memorize the association between lever-manipulation and a reward. This associative relationship was additionally associated with a visual stimulus. This design mimics instrumental activity of daily living. For example, we raise a coffee cup to make coffee and then to drink, where raising the cup gets increasingly associated with drinking indirectly and directly with each repetition. Thereby, just when we wanted to drink a cup of coffee, the memories structured centering on the cup are efficiently retrieved in a goal-directed manner on the basis of external information. Thus, the 2AFC visual detection task is suitable for constructing the multiply-associative memory structure established by our daily routine. After completion of the task learning within 10 days and a subsequent task training period for one month, the effects of scopolamine (SCOP), an mAChR antagonist, on task performance was examined. We define the memory used in daily routine after completion of the learning as a well-trained memory.

SCOP was chosen because of comprehensive comparison of ours with a lot of previous studies examining the effects on memory-related functions other than well-trained memory and various cognitive functions (Hodges et al., 2009; Klinkenberg and Blokland, 2010). We also tested the effects of bloodbrain barrier (BBB) impermeable scopolamine methyl-bromide (methyl-SCOP) and an m1-specific AChR antagonist to exclude the several possible effects of SCOP such as salivation and attention (Klinkenberg and Blokland, 2011). We adopted systemic administration of SCOP to mimic AD patients, as they generally suffer from diffuse and global impairment of cholinergic functions (Whitehouse et al., 1981, 1982).

SCOP caused severe impairment of performance, as rats temporarily and specifically lost task-related memories about the two associations, but recalled them over time in the order they were learned. Our results demonstrate that activation of $\mathrm{mAChRs}$ with basal levels of ACh is essential for the retrieval of well-trained cognitive memory established by daily routine.

\section{MATERIALS AND METHODS ANIMALS}

Twenty male Long-Evans rats (Institute for Animal Reproduction, Ibaraki, Japan) were kept on $12 \mathrm{~h}$ light/dark cycles, and tests were performed during the light cycle. All experimental protocols were approved by the Research Ethics Committee of Osaka University, and all procedures were carried out in compliance with the policies and regulations of the guidelines approved by the Animal Care Committee of the Osaka University Medical School and National Institutes of Health guidelines for the care of experimental animals.

\section{WATER CONTROL}

Animals had ad libitum access to water during weekends, but obtained water only by performing the task correctly on other days. Signs of possible dehydration were monitored (reduced skin tension, sunken eyes, and marked variations in general behavior), but none were observed in all animals. To ensure adequate hydration, we weighed each animal at the beginning and end of each experimental session and compared the weight to a standard weight updated weekly. If the weight measured after the session was $<90 \%$ the standard weight, the animal would be temporarily taken out of the study and given ad libitum access to water until the weight recovered. This condition never occurred. Average $\pm S D$ of body weights were $296 \pm 14 \mathrm{~g}$ and $431 \pm 12 \mathrm{~g}$ before and after learning and training phases, respectively.

\section{APPARATUS IN 2AFC TASK}

The choice-box (Figure 1A; $30 \mathrm{~cm}$ long $\times 40 \mathrm{~cm}$ high $\times 55 \mathrm{~cm}$ wide) was made as described in detail elsewhere (Soma et al., 2013c). The front side of the box was translucent and faced an LCD monitor (mean luminance, $30 \mathrm{~cd} / \mathrm{m}^{2}$ ). The box was divided by translucent walls to produce three connected areas that each had a spout-lever in its center: a central-lever in the middle area and choice-levers in the other two. To shorten the learning period, we used the spout-lever as an operandum (Kimura et al., 2012) by which rats were able to learn rapidly that pulling it upward correlated with acquisition of the reward. The reward volume was changed by controlling the open time of a solenoid valve that was manipulated by a PC. Speakers attached to the monitor gave signals indicating task initiation and auditory feedback of a task error. Animal behavior was monitored through a webcam. Software for the experimental control and stimulus presentation was written in MATLAB (Mathworks, Natick, MA, USA) with extensions from the Psychophysics Toolbox (Brainard, 1997; Pelli, 1997).

\section{BEHAVIORAL TASK FOR THE MEMORY RETRIEVAL TEST}

We used the 2AFC visual detection task in order to examine the cholinergic effect on memory retrieval. Rats began each trial by pulling upward the central-lever, which triggered the presentation of a circular patch of static sinusoidal grating to the right or left side of the display monitor (Figure 1A). The viewing distance of the stimulus center from the central-lever was $13 \mathrm{~cm}$. The parameters of vertical grating (spatial frequency, 0.1 cycles/degree; diameter, 70 degrees) were determined according to our previous study (Soma et al., 2013c). The stimulus presentation continued until the rat pulled upward any choice-lever. The grating location was randomly changed from trial to trial. Upon a correct choice, rats received a reward of $2-5 \mu \mathrm{L}$ of water. Upon an incorrect choice, rats only received an audible sound $(200-500 \mathrm{~Hz})$. All animals performed at least 100 trials for $20 \mathrm{~min}$ under the no drug condition (median, 181 trials; range, 100-300 trials). Rat performance (\% Hit) was calculated every $5 \mathrm{~min}$ by dividing the number of correct trials by that of total trials. In the recovery experiments (Figures $\mathbf{2 B}, \mathbf{C}, \mathbf{3 A}, \mathbf{B}$ ), rats were tested for the task performance at $0.5,3$, and $6 \mathrm{~h}$ after drug injection, in which, each test were conducted for $20 \mathrm{~min}$. In the intervals between the test, rats were returned to their home cages.

\section{LEARNING AND LONG-TERM TASK TRAINING PERIODS}

Training procedures for learning the 2AFC visual detection task are described in detail elsewhere (Soma et al., 2013c). Briefly, rats 
A

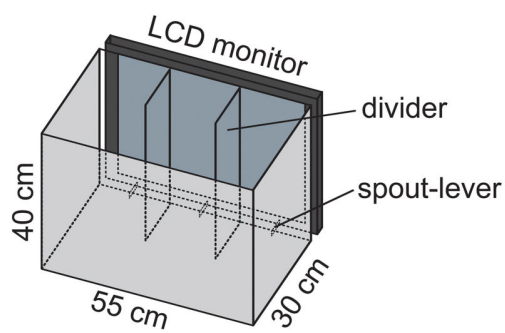

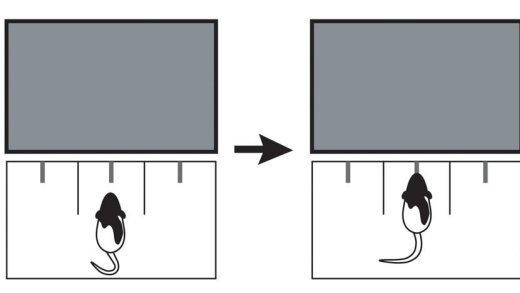

Central-lever manipulation

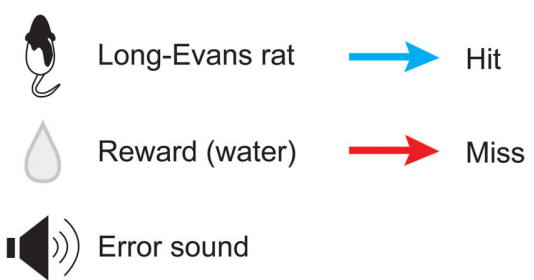

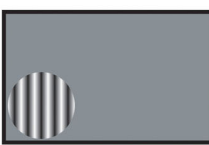
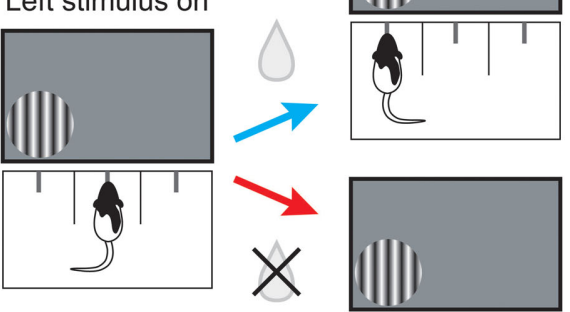

I.1)
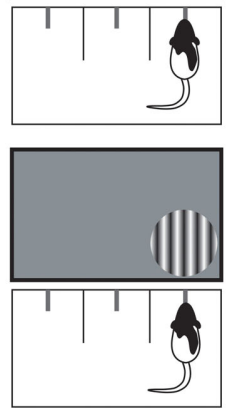

Right stimulus on
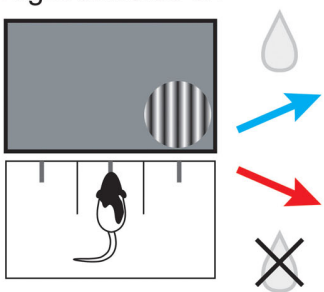

(1))

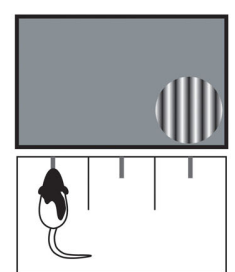

B

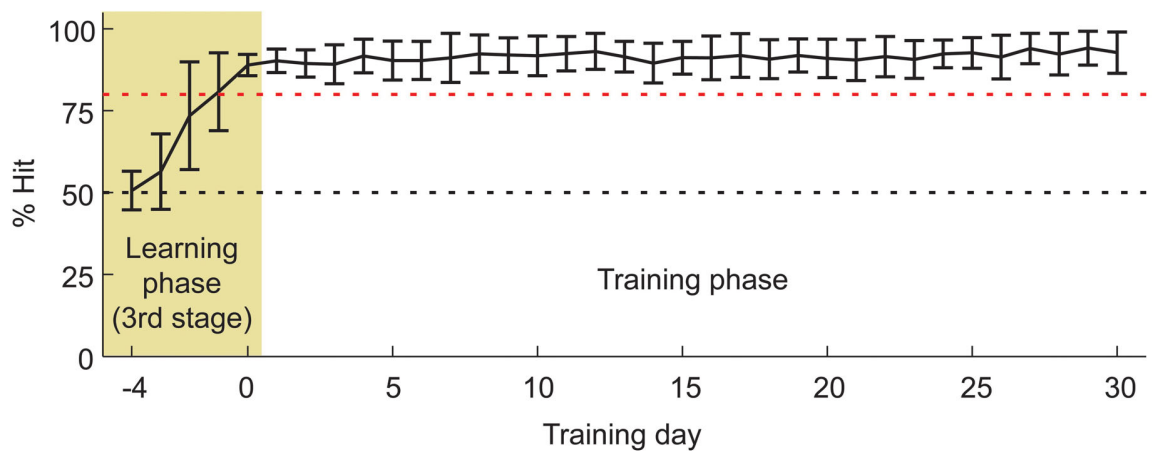

FIGURE 1 |Assessment of well-trained memory by the 2AFC visual detection task. (A) Schema of the visual stimulus detection task based on a 2AFC paradigm. First, the rat pulled central-lever up for presenting the visual stimulus. Next rat was required to detect the stimulus and pull the corresponding choice-lever upward. When the animal made a correct choice (Hit), water was rewarded from the choice-lever. In the case of an incorrect choice (Miss), only an error signal was given. The schematic illustration of the choice-box is depicted in upper left (see Methods for details). (B) Animal's learning and training processes. Animals $(n=20)$ learned a visual stimulus detection task over 5 learning days (pale yellow area, Learning phase), and the same task was subsequently continued for another 30 days (open area, Training phase). Red dashed line indicates $80 \%$ Hit. Data are presented as mean $\pm S D$. were trained in three stages. In the first stage (1-2 days), all rats $(n=20)$ learned to obtain fluid delivered from the spout-lever by pulling it upward in a single choice-box isolated from the other areas. A rat was put into the choice-box $1 \mathrm{~h}$ per day, in which the bigger reward $(10 \mu \mathrm{L})$ was delivered automatically every $30 \mathrm{~s}$ or by pulling the spout-lever up. The rat was easily able to learn how to acquire the reward by heuristic manipulation of the spoutlever. In the second stage (3-6 days), the rats learned how to initiate and obtain fluid during the trial in the normal choicebox used for the 2AFC task (see Figure 1A). The rat learned to 
A

$$
\begin{aligned}
& \text { SCOP } \\
& =0 \mathrm{mg} / \mathrm{kg} \text { (Saline) } \\
& \square 0.02 \mathrm{mg} / \mathrm{kg}
\end{aligned}
$$

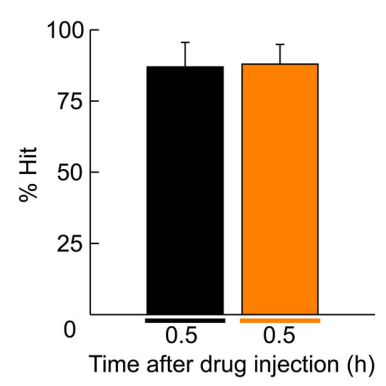

E
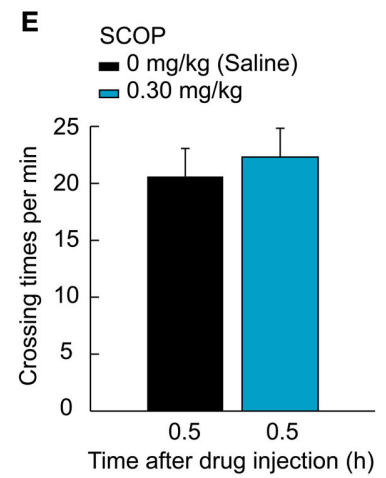

B

SCOP

- $0 \mathrm{mg} / \mathrm{kg}$ (Saline)

$=0.10 \mathrm{mg} / \mathrm{kg}$

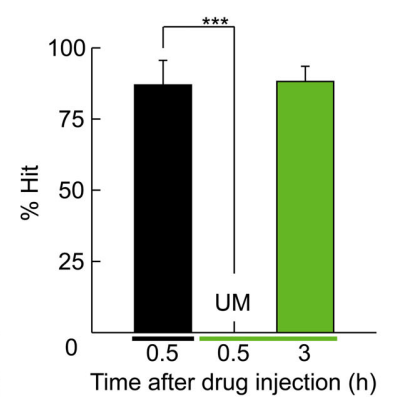

$\mathbf{F}$
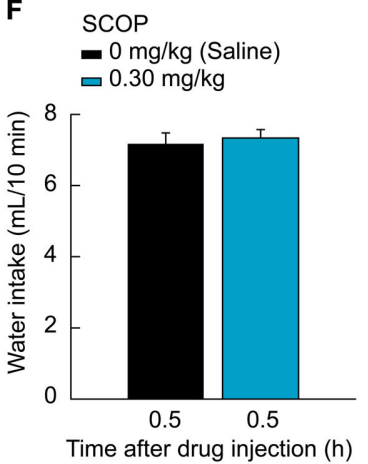

C
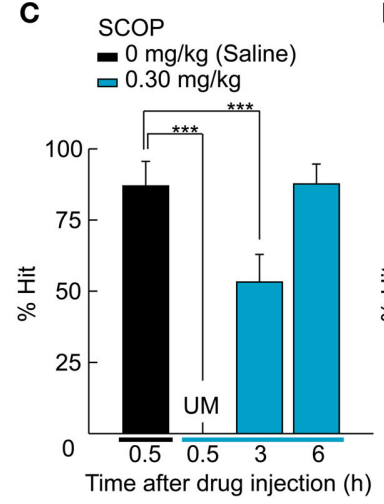

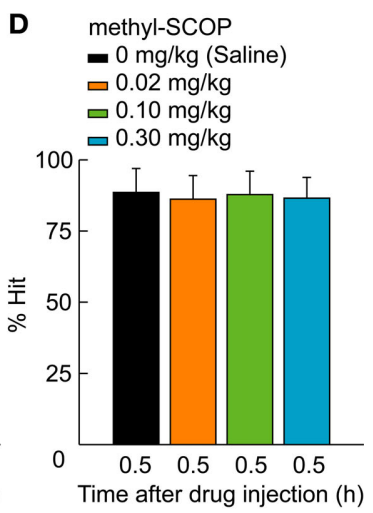

G

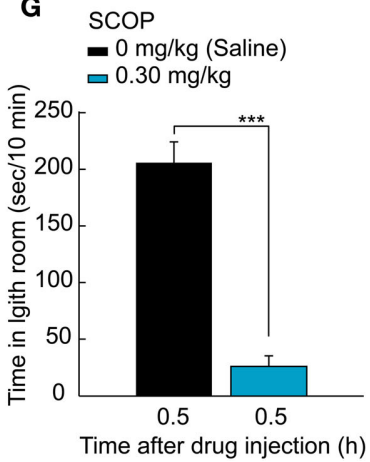

H

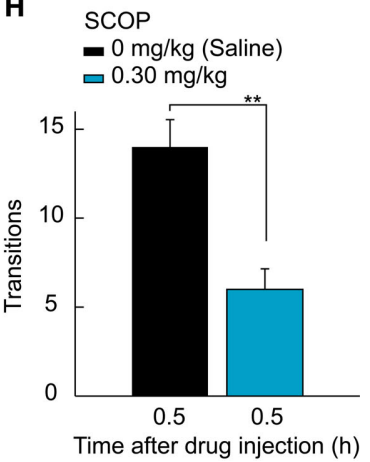

FIGURE 2 | SCOP-induced temporary blackout of well-trained memory. (A-D) Rat performance tested after the injection of saline and various doses of SCOP or methyl-SCOP $(0.02,0.1$, and $0.3 \mathrm{mg} / \mathrm{kg})$. Rats never manipulated the lever $0.5 \mathrm{~h}$ after 0.10 or $0.30 \mathrm{mg} / \mathrm{kg}$ SCOP administration, as behavioral performance was unmeasurable (UM; B,C). In contrast, $0.02 \mathrm{mg} / \mathrm{kg} \mathrm{SCOP}$ and all doses of methyl-SCOP did not affect performance $(\mathbf{A}, \mathbf{D})$. At $3 \mathrm{~h}$ after SCOP injection, rats remembered

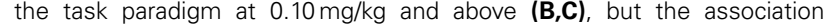
between the lever and reward only at $0.30 \mathrm{mg} / \mathrm{kg}$ (C). (E,F) High concentration of SCOP $(0.30 \mathrm{mg} / \mathrm{kg})$ affects neither the amount of locomotor activity level measured in an open field nor the water intake from a regular water bottle. (G,H) SCOP injection at $0.30 \mathrm{mg} / \mathrm{kg}$ influenced anxiety. Data are presented as mean $+S D$; ${ }^{* *} P<0.01$. ${ }^{* * *} P<0.001 . n=10$ rats/group. pull the central-lever up before the choice-lever (task initiation), which presented a grating. When either choice-lever was pulled up before the central-lever, an error-sound $(200-500 \mathrm{~Hz})$ was given as an instructive feedback signal. After the task initiation, the grating presentation continued until the rat pulled upward the correct choice-lever by which fluid was delivered. Thereby, a rat learned sequential manipulation of the central and choicelevers to obtain the reward. In the third stage (6-10 days), rats learned that the fluid supply is associated with the visual stimulus. During the training period of the task, rats learned the following in a stepwise fashion: association between (1) lever-manipulation and the reward, and (2) visual stimulus and the reward. The task device was developed to efficiently obtain well-trained memory by securing a sufficient length of training period and number of task repetitions (Soma et al., 2013c). Furthermore, our device provided a great number of repetitive training within a short time without task interruption by human handling.

We judged the completion of task learning when the success rate reached more than $80 \%$ in the total trials of one day. This stage is indicated by the pale yellow area in Figure 1B (Learning phase, days -4 to 0 ; Third stage, $6-10$ days). The task was continued for another 30 days in the training phase (open area, days
1-30; Figure 1B) for the purpose of examining the effects of the cholinergic blockade on well-learned behavioral functions established daily routine. The task conditions of the training phase were the same as those of the memory retrieval test, and rats performed 300 trials within a session (60-min cutoff).

\section{PHARMACOLOGICAL TREATMENTS}

The role of the cholinergic system in the retrieval function was assessed using ACh-relevant drugs. All drugs were administered intraperitoneally with an injection volume of $1 \mathrm{ml} / \mathrm{kg}$ prior to the behavioral test. Drugs were dissolved in $0.9 \%$ saline to create appropriate stock solutions. SCOP (Sigma-Aldrich, St. Louis, MO, USA), an antagonist of $\mathrm{mAChRs}$ that permeates the BBB, and methyl-SCOP (Sigma-Aldrich, St. Louis, MO, USA), an antagonist of $\mathrm{mAChRs}$ that is impermeable of the $\mathrm{BBB}$, were given at three doses $(0.02,0.10$, and $0.30 \mathrm{mg} / \mathrm{kg})$ and administered $0.5 \mathrm{~h}$ prior to the test. The doses of SCOP were chosen based on previous studies (Chopin and Briley, 1992; Kaneko and Thompson, 1997; Hodges et al., 2009; Klinkenberg and Blokland, 2011). In the rescue study, donepezil (Eisai, Ibaraki, Japan), a cholinesterase inhibitor, was given at $1.0 \mathrm{mg} / \mathrm{kg}$ (Takahata et al., 2005; Wise et al., 2007). At $0.5 \mathrm{~h}$ after the donepezil administration, $0.30 \mathrm{mg} / \mathrm{kg}$ 

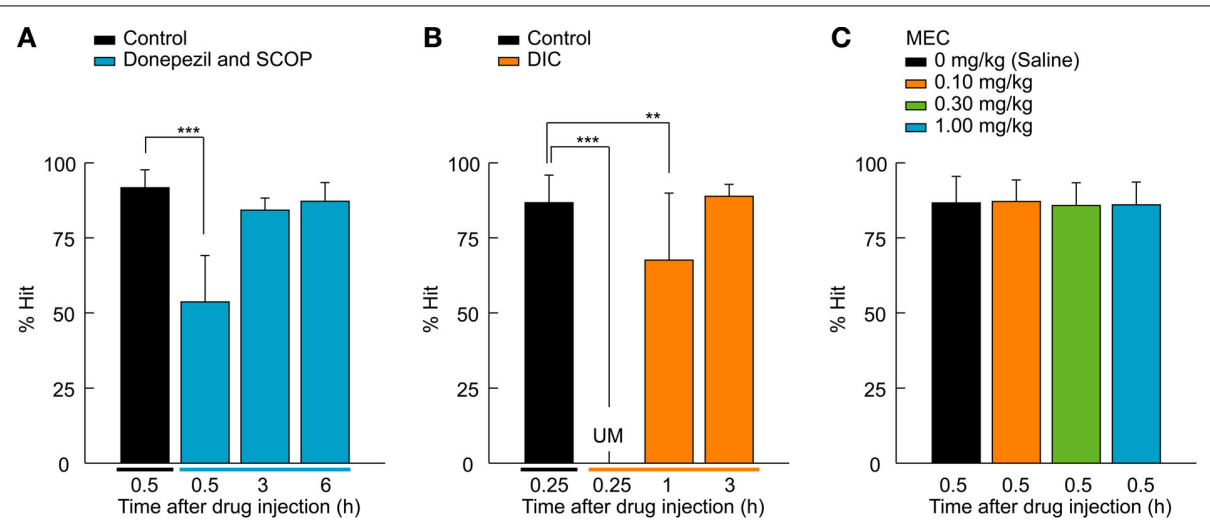

FIGURE 3 | M1 AChR-mediated retrieval function of the 2AFC task. (A) A cholinesterase inhibitor, donepezil $(1.0 \mathrm{mg} / \mathrm{kg})$, was systemically administered to rats a half-hour before SCOP injection $(0.30 \mathrm{mg} / \mathrm{kg})$. Donepezil attenuated the effect of SCOP on the performance of the 2AFC task, as rats were able to recall the association between lever-manipulation and reward even $0.5 \mathrm{~h}$ after the SCOP injection and perform the 2AFC task after $3 \mathrm{~h}$ equally to that of the control condition. $n=5$ rats/group. (B) DIC $(8.0 \mathrm{mg} / \mathrm{kg})$, an m1-specific AChR antagonist, was tested using the 2AFC task. The same effects as SCOP were seen, but in a shorter time course. $n=5$ rats/group. (C) MEC, an nAChR antagonist, did not influence rat performance. $n=10$ rats/group. Data are presented as mean $+S D ;{ }^{* *} P<0.01$. ${ }^{* * *} P<0.001$.
SCOP was given $0.5 \mathrm{~h}$ prior to the $2 \mathrm{AFC}$ test. Other pharmacological studies were carried out using $8.0 \mathrm{mg} / \mathrm{kg}$ dicyclomine (DIC; Sigma-Aldrich, St. Louis, MO, USA), an m1-specific AChR antagonist (Bartko et al., 2011), and 0.1, 0.3, and $1.0 \mathrm{mg} / \mathrm{kg}$ mecamylamine (MEC; Sigma-Aldrich, St. Louis, MO, USA), an $\mathrm{nAChR}$ antagonist. The former and latter were given 0.25 and $0.5 \mathrm{~h}$ before the test, respectively. In all pharmacological studies, $0.9 \%$ saline was injected as a control at the same time points as the drug administration.

All pharmacological studies were conducted in within-subjects design. Rats were assigned to either SCOP/methyl-SCOP test group (Figures 2A-D) or other drugs test group (Figure 3). In the SCOP/methyl-SCOP test, data were obtained from 10 rats. After the 30-day training phase, the rats were tested by a crossed Latin square design including 2 control conditions (1: vs. SCOP and 2: vs. methyl-SCOP), 3 doses of SCOP conditions and 3 doses of methyl-SCOP conditions (total 8 conditions/rat). Individual rats were tested for all the 8 conditions in the pseudo-random order through days $31-38$. These ten rats were subsequently subjected to the other types of tests including open field test, water intake, and light-dark room test by a crossed Latin square design (Figures 2E-H). This battery of tests consisted of 6 conditions, derived from 2 drug conditions (control and $0.3 \mathrm{mg} / \mathrm{kg} \mathrm{SCOP}$ ) for 3 test types $(2 \times 3$ conditions/rat $)$. The all the testes were done at $0.5 \mathrm{~h}$ after the administration of saline or SCOP through days $39-44$, in which the order of the tests were pseudo-randomly assigned to individual rats.

Among 10 rats of other drugs test group, 5 rats were assigned to the donepezil test (Figure 3A), another 5 to the DIC test (Figure 3B), and the both of them $(n=10)$ were used in the MEC test (Figure 3C). These rats too were tested by a crossed Latin square design including 2 control conditions (1: vs. donepezil + SCOP, or vs. DIC; 2: vs. MEC), either the donepezil or DIC condition, and MEC conditions at 3 doses in the pseudorandom order through days 31-36 (total 6 conditions/rat). In all the pharmacological tests, each rat underwent one test a day.

\section{OPEN FIELD TEST}

The locomotor activity level was measured in an open field. The test field was a circle of $60 \mathrm{~cm}$ in diameter and was surrounded by a wall of $30 \mathrm{~cm}$ in height. The entire field was monitored from above by a webcam which was connected to a PC for the recording of behavior. Each rat was placed in the center of the test field, and the rat's behavior was recorded in video. The activity level was analyzed off-line by an observer blind to the experimental conditions. The circular test field was divided into nine zones; each rat's activity level was measured as the total number of crossovers between zones (i.e., crossing a boundary line between zones with two hind paws) for $5 \mathrm{~min}$. The open field test was conducted under two drug conditions, saline and SCOP $(0.30 \mathrm{mg} / \mathrm{kg})$.

\section{MEASUREMENT OF WATER INTAKE}

The degree of dehydration was examined by measuring the water intake for $5 \mathrm{~min}$. At $0.5 \mathrm{~h}$ after the administration of saline or $0.30 \mathrm{mg} / \mathrm{kg}$ SCOP, rats were placed in the home cage and had ad libitum access to water from a regular bottle. Water intake was measured as the weight loss of the bottle.

\section{LIGHT-DARK ROOM TEST}

A light-dark room test was performed to examine whether SCOP influences anxiety and impairs light perception. The test was conducted under two drug conditions, saline and SCOP $(0.30 \mathrm{mg} / \mathrm{kg})$. The apparatus was a plastic box $(48 \mathrm{~cm}$ long $\times 24 \mathrm{~cm}$ high $\times 27 \mathrm{~cm}$ wide) consisting of two equal-size compartments in which rats could freely move between through an open gate $(10 \mathrm{~cm}$ high $\times 10 \mathrm{~cm}$ wide). The sides of the box were opaque, and the top was covered with an opaque lid for the dark room condition and a transparent lid for the light room condition. The light room was illuminated with a $27-\mathrm{W}$ fluorescent lamp set $40 \mathrm{~cm}$ above the box (mean luminance, $40 \mathrm{~cd} / \mathrm{m}^{2}$ ). Rats were placed in the center of the light room and allowed to freely explore the box. After the rats entered the dark room, the number 
of transitions and the time spent in the light room were measured for $10 \mathrm{~min}$.

\section{STATISTICAL ANALYSES}

We used the Kolmogorov-Smirnov test to test the goodness of fit of a given set of data to a theoretical distribution. In the 2AFC task, normally distributed data were analyzed by one-way analysis of variance (ANOVA) for repeated measures followed by post hoc Dunnett's test with comparison to the control group. Data not showing a normal distribution were analyzed by the nonparametric Friedman test. Further statistical analyses for individual groups were carried out by the Wilcoxon signed-rank test with the Bonferroni correction. Statistical analyses of other measures obtained from the open field test, the light-dark room test, and water intake were carried out using the Wilcoxon signed-rank test.

\section{RESULTS}

\section{RATS ACQUIRE WELL-TRAINED COGNITIVE MEMORY BY REPETITIVE TRAINING OVER THE LONG-TERM}

In order to investigate the functional roles of ACh in the retrieval process of well-trained memory established from daily routine, we adopted operant conditioning based on a $2 \mathrm{AFC}$ visual detection task that requires cognitive procedures in a behavioral choice-box (Figure 1A; Movie S1; Soma et al., 2013c). The improvement of learning was assessed as the success rate (\% Hit), and the learning completion was defined as $\%$ Hit larger than $80 \%$ (pale yellow area, Learning phase; Figure 1B). The training phase was set to last one month after completion of the learning task. During this time, the rats continued to perform the visual stimulus detection task at a high performance (open area, Training phase; Figure 1B). After the 30-day training phase, the performance of the well-trained rats was tested with or without SCOP $(0.02,0.10$, and $0.30 \mathrm{mg} / \mathrm{kg}$; Figure 2A).

\section{SCOP IMPAIRS THE RETRIEVAL OF WELL-TRAINED MEMORY}

SCOP had a concentration-dependent effect on the retrieval function (Figures 2A-C). Low concentration of SOCP $(0.02 \mathrm{mg} / \mathrm{kg})$ did not affect behavioral performance $(P=0.406$, Wilcoxon signed-rank test; Figure 2A), whereas middle and high concentrations $(0.10$ and $0.30 \mathrm{mg} / \mathrm{kg})$ had a strong negative effect on performance $\left(\chi^{2}=60.2, d f=2, P<0.001\right.$, Figure 2B; $\chi^{2}=109.1$, $d f=3, P<0.001$, Friedman test; Figure 2C). We were not able to measure rat performance $0.5 \mathrm{~h}$ after SCOP administration, because the rats never manipulated the lever at the time $(P<0.001$, Figure 2B; $P<0.001$, Wilcoxon signed-rank test with Bonferroni correction; Figure 2C), suggesting that they had forgotten what they had learned, i.e. the association between the lever-manipulation and task initiation/reward acquisition (see Movie S2). However, SCOP has been known to dilate pupil which might impair visual perception. To confirm whether SCOP caused its effects by acting on the central nervous system, we tested methyl-SCOP, which is an $\mathrm{mAChR}$ antagonist that is impermeable to the BBB. The same doses of methyl-SCOP as SCOP $(0.02,0.10$, and $0.30 \mathrm{mg} / \mathrm{kg})$ did not affect behavioral performance $\left[F_{(3,77)}=0.4, P=0.766\right.$, one-way ANOVA for repeated measures; Figure 2D]. To rule out the possibility that SCOP influences motor function and dehydration, we performed an open field test and a measurement of water intake, respectively. SCOP $(0.30 \mathrm{mg} / \mathrm{kg})$ neither affected the amount of locomotor activity $(P=0.313$, Wilcoxon signed-rank test; Figure 2E) nor water intake $(P=0.732$, Wilcoxon signed-rank test; Figure $2 \mathbf{F})$. These results suggest that the unmeasurable performance of the 2AFC task was induced via mAChRs in the central nervous system and not due to functional changes in the peripheral nervous system or motor impairment. SCOP has been known to increase anxiety. Therefore, we conducted the light-dark room test. The SCOPinjected group stayed significantly longer in the dark room than the control group (time in light room, $P<0.001$; transitions, $P<0.01$, Wilcoxon signed-rank test; Figures $\mathbf{2 G}, \mathbf{H}$ ), indicating an anxious tendency.

Recovery from the SCOP-induced task impairment showed different time courses in a dose-dependent manner. At $3 \mathrm{~h}$ after the drug administration, the task performance was completely recovered $(P=0.429$, Wilcoxon signed-rank test with Bonferroni correction; Figure 2B) at $0.10 \mathrm{mg} / \mathrm{kg}$. On the other hand, the performance at $0.30 \mathrm{mg} / \mathrm{kg}$ was chance level $(P<0.001$, Wilcoxon signed-rank test with Bonferroni correction; Figure 2C), because rats were able to pull the central-lever upward to start the task, but selected the choice-lever randomly (Movie S3). This result argues that under this situation rats could remember the association between the central-lever manipulation and task initiation, but not the association between the visual stimulus and reward. A further $3 \mathrm{~h}$ later ( $6 \mathrm{~h}$ after the drug administration), rats could perform the task at control level $(P=0.315$, Wilcoxon signedrank test with Bonferroni correction; Figure 2C). Thus, recall of the association memories did not occur simultaneously, suggesting that the accessibility of the memories differ, with lower accessibility requiring more $\mathrm{ACh}$ for memory retrieval.

\section{RESCUE OF TEMPORAL AMNESIA BY DONEPEZIL}

Next we investigated if a cholinesterase inhibitor, donepezil, was able to rescue the impairment of the task performance (Figure 3A). Rats were systemically injected with donepezil $(1.0 \mathrm{mg} / \mathrm{kg}) 0.5 \mathrm{~h}$ before the $0.30 \mathrm{mg} / \mathrm{kg}$ SCOP administration. The 2AFC visual detection task was conducted using the same time course as the SOCP alone injection experiments described in Figure 2C. SCOP still exerted an effect $\left[F_{(3,77)}=83.7\right.$, $P<0.001$, one-way ANOVA for repeated measures; Figure 3A], but the effect was attenuated by the pre-administration of donepezil. \% Hit under the co-administration condition was chance level $(P<0.001$, Dunnett's post hoc test $)$ at $0.5 \mathrm{~h}$ after the SCOP injection, whereas it was unmeasurable in the SCOPonly condition (see Figure 2C). Additionally, the recovery time of the behavioral performance was shortened, as $3 \mathrm{~h}$ after the drug co-administration, rats could perform the visual stimulus detection task without significant differences from the control condition ( $3 \mathrm{~h}, P=0.411 ; 6 \mathrm{~h}, P=0.486$; Dunnett's post hoc test; Figure 3A).

\section{M1-AChR-MEDIATED TEMPORAL AMNESIA}

To investigate whether m1-AChRs, an mAChR subtype, contribute to the retrieval function, we tested the effect of DIC $(8.0 \mathrm{mg} / \mathrm{kg})$, an $\mathrm{m} 1$-specific AChR antagonist (Figure 3B). DIC caused the same effect as SCOP $\left(\chi^{2}=44.9, d f=2, P<0.001\right.$, 
Friedman test; Figure 3B), but over a shorter time course. Rats suffered a temporary blackout with regards to the association between the lever and reward $0.25 \mathrm{~h}$ after the DIC administration $(P<0.001$, Wilcoxon signed-rank test with Bonferroni correction), but remembered the association at $1 \mathrm{~h}$ after the administration $(P<0.01$, Wilcoxon signed-rank test with Bonferroni correction). After $3 \mathrm{~h}$, the behavioral performance was completely recovered $(P=0.353$, Wilcoxon signed-rank test with Bonferroni correction). These observations suggest that the memory retrieval function of ACh is at least mediated by m1-AChRs. Finally, we examined whether $\mathrm{nAChR}$ are involved in the retrieval function by using MEC, an nAChR antagonist. All tested doses (0.1, 0.3 , and $1.0 \mathrm{mg} / \mathrm{kg}$ ) of MEC had no effect on rat performance $\left[F_{(3,77)}=0.6, P=0.634\right.$, one-way ANOVA for repeated measures; Figure $3 \mathrm{C}]$.

\section{DISCUSSION}

To investigate the possibility that cholinergic deficiency is involved in various cognitive deficits of progressed AD patients, that is, impairment of well-learned functions expressed frequently in daily living, we examined the effects of cholinergic blockade on well-trained memory established by daily routine. After rats learned the $2 \mathrm{AFC}$ visual detection task within 10 days, the task training was continued every day for a month. After the training phase, the effect of systemic administration of SCOP on the 2AFC visual detection test was examined. The results are summarized as follows: (1) middle and high doses of SCOP $(0.1$ and $0.3 \mathrm{mg} / \mathrm{kg})$ caused an impairment of task performance, as rats showed no task initiation due to no lever-manipulation at $0.5 \mathrm{~h}$ and only haphazard selection of the choice-lever after task initiation at $3 \mathrm{~h}$ post SCOP administration; (2) rats started to perform the task over time in the order the tasks were learned; (3) pre-administration of donepezil attenuated the SCOP-induced temporal task impairment; and (4) blockade of m1-AChRs but not nAChRs caused the impairments similar to those from SCOP administration.

\section{ROLE OF ACh IN MEMORY RETRIEVAL}

Although many researchers have examined how ACh contributes to memory functions such as encoding and consolidation (Miranda and Bermudez-Rattoni, 1999; Nail-Boucherie et al., 2000; Wallenstein and Vago, 2001; Gold, 2003; Rogers and Kesner, 2003; Bang and Brown, 2009; Pang et al., 2010; Pepeu and Giovannini, 2010), there are few studies that have investigated the role of the cholinergic system in memory retrieval (Zarrindast et al., 1996; Marti Barros et al., 2004; Soares et al., 2006; Piri and Zarrindast, 2011). Since those studies focused mainly on aversively motivated tasks, it remains poorly understood how other type of memory is modulated by ACh and which type of AChR subtype mediates the action. This study provides the first evidence that activation of mAChRs, at least m1-AChRs, is necessary to retrieve well-trained memory. M1-AChRs-dependent memory retrieval has also been reported for recently acquired memory formed during aversively motivated tasks. Soares et al. (2006) demonstrated that pre-test administration of DIC impaired the retrieval of memory acquired from contextual fear conditioning but not from inhibitory avoidance task, suggesting taskdependent differential contributions of m1-AChRs. On the other hand, the memory retrieval in inhibitory avoidance task seems to be mediated via nAChRs, because the latency of mice for entering a dark room that contained footshock is increased by the systemic administration of nicotine (Zarrindast et al., 1996; Marti Barros et al., 2004; Piri and Zarrindast, 2011) and decreased by the antagonistic blockade of nAChR (Zarrindast et al., 1996; Marti Barros et al., 2004). Thus, retrieval functions can be mediated by different AChRs depending on the type of memory.

\section{MEMORY FORMED BY A LONG-TERM DAILY TRAINING}

In general, animals trained more than the number of the training session required for the completion of task learning is considered as overtrained animals. Although the overtrained animals reach the plateau in the task performance, overtraining-induced plastic changes in nervous system have been known to continue and vary in quantity and quality depending on the number of session (Luft and Buitrago, 2005), for example, the overtraining of water maze increased synaptogenesis of hippocampal mossy fibers according to the session number (Ramírez-Amaya et al., 1999). Thus, neuronal plastic changes are thought to continue in contrast with an impression of the term "overtraining" that training-induced plastic change plateaus not followed by additional change. Moreover, it has been known that extensive training causes a transformation from goal (reward)-directed actions into habitual responses of animals (Yin and Knowlton, 2006). For example, hungry rats are trained to press a lever in order to obtain sucrose pellets, and post training devaluation of the pellets by conditioned taste aversion causes a reduction in lever-pressing after moderate training but not after extensive training (Dickinson, 1985), suggesting that the behavior is still goal-directed after the moderate training and becomes habitual after the extensive training. In that case, brain areas, networks, and synaptic transmission responsible for task-relevant memories are thought to change depending on the training conditions such as the number and period of training. Therefore, the cholinergic sensitivity of the task-relevant memory should be evaluated in the same task at different amounts of the training. In the present study, rats seemed to perform the task in a reward-directed manner since rats stopped executing the task when rat's thirst was quenched with the water even after 30 days training phase. However, there are important questions about whether the reward-directed behavior is transformed into habitual responses if the training period increased further, and if so, whether cholinergic blockade is effective on the task performance. Those points should be examined in further study.

\section{SIDE EFFECTS OF SCOP}

SCOP has been reported to have cognitive as well as noncognitive effects (Bushnell et al., 1997; Sipos et al., 1999; Mirza and Stolerman, 2000; Phillips et al., 2000; Hodges et al., 2009; Klinkenberg and Blokland, 2010). In the present study, we performed an open field test, and a measurement of water intake in order to rule out the possibility that SCOP influences motor function, and dehydration, respectively. SCOP $(0.3 \mathrm{mg} / \mathrm{kg})$ did not impair motor function, as the amount of locomotor activity in the open field was not different between control and SCOP conditions (Figure 2E). In the choice-box, SCOP-administered rats 
seemed to have reduced activity (Movie S2) in comparison with control rats (Movie S1). However, this observation does not mean that SCOP caused the low activity, because the same behavioral pattern and activity were observed when naïve rats unlearning the task were put in the choice-box. We propose that the speedy action and high activity of well-trained rats are more likely due to their reward-directed and well-motivated behavior.

It is known that SCOP has a "dry mouth" side effect that reduces salivation (Dai et al., 1991; Shiraishi and Takayanagi, 1993; Hodges et al., 2009). However, this effect is unlikely to explain the absence of task initiation seen in the present report for several reasons. First, the reward was water, not dry food; second, the water intake was not affected by administration of $0.3 \mathrm{mg} / \mathrm{kg}$ SCOP (Figure 2F); and third, methyl-SCOP, which has the same peripheral side effects as SCOP (Hodges et al., 2009), did not impair execution of the task (Figure 2D).

Since visual information processing is modulated by ACh (Goard and Dan, 2009; Kang et al., 2013; Soma et al., 2013a,b,c), the light-dark room test was conducted to examine whether SCOP impairs the light perception. If SCOP did induce visual impairment, rats should stay in the dark and light rooms equally. However, rats stayed in the dark room longer, suggesting that SCOP-administered rats were able to perceive light (Figures 2G,H). In addition, Tsui and Dringenberg (2013) found that SCOP at a dose of $1.0 \mathrm{mg} / \mathrm{kg}$, which is higher than that used in the present study, did not impair performance in visual discrimination tasks that used striped textures as stimuli.

The other side effect of SCOP is pupil dilatation, which might influence the task performance by making rats blind in bright light. However, the pupil dilatation does not seem to be responsible for SCOP-induced deficit in the task execution because methyl-SCOP was reported to dilate the pupil twice as effective as SCOP (Jones and Higgins, 1995) but not impaired the task performance in this study (Figure 2D). Therefore, SCOP seems not to impair the visual detection in our experimental conditions.

In the light-dark room test, SCOP-injected rats stayed significantly longer in the dark room compared to control rats, implying the appearance of anxiogenic-like behavior (Klinkenberg and Blokland, 2010). A similar symptom has been reported in previous rat studies observing rats (Smythe et al., 1996; Hughes et al., 2004) as well as humans (Curran et al., 1991), showing increased anxiety as well as amnestic effects by SCOP. However, anxiogenic-like behavior was not a major cause of our observations, because SCOP-injected rats moved around and explored the surrounding environment inside the choice-box including the levers (Movie S2).

\section{POSSIBLE INFLUENCE OF SCOP ON COGNITIVE FUNCTIONS}

SCOP is known to impair cognitive functions such as working memory and attention (Bushnell et al., 1997; Hodges et al., 2009). In the present study, working memory was not required to perform the $2 \mathrm{AFC}$ visual detection task, but attention might be needed depending on the stimulus condition. In a visual detection task, the difficulty of the stimulus detection is correlated with demand of attentional capacity. For example, SCOP slightly impaired the performance in an easy visual cue detection task without distracter but severely disrupted it when distracter was simultaneously presented (Jones and Higgins, 1995). Since task difficulty can be manipulated by changing the stimulus parameters (Soma et al., 2013c), we set the easiest stimulus condition (see Materials and Methods) to lessen the possibility that SCOP effects on attention contributed to the task performance. The cholinergic system is also involved in sustained attention (Bushnell et al., 1997; Parikh et al., 2007). In those studies, animals were required to sustain their attention to detect an unexpected visual cue, under which cue detectability was associated with cortical ACh content (Parikh et al., 2007). However, in our study, the sustained attention for stimulus detection is not required, because the visual stimulus was presented by the rat's centrallever manipulation. Klinkenberg and Blokland (2011) reported that m1-specific AChR antagonist is better than SCOP to cause mnemonic deficits because of the small effect on attentional function. Since DIC as well as SCOP caused severe impairment of the task performance in this study, we believe that the SCOP-induced deficit in the task execution is not due to an impairment of the working memory and attentional functions.

\section{NEURAL MECHANISMS UNDERLYING CHOLINERGIC REGULATION OF MEMORY RETRIEVAL}

How is ACh involved in the retrieval of well-trained memory? Various kinds of long-term memory including personal experience (Penfield, 1952) and experimentally-experienced visual stimuli (Hasegawa et al., 1998) are stored in the neocortex and retrieved by glutamatergic top-down signals from the prefrontal cortex (Hasegawa et al., 1998). These corticocortical feedback connections, which convey top-down signals, project to extragranular layers where mAChRs are richly expressed (Levey et al., 1991). Consistent with this structure, we found that SCOP, but not MEC, impaired the recall of well-trained memory. Cortical ACh originating in the nucleus basalis of the basal forebrain (Saper, 1984) could allow focused memory to be easily retrieved by the glutamatergic system by regulating the dynamics of the neuronal network via activation of mAChRs but not nAChRs.

\section{SIGNIFICANCE OF THE PRESENT STUDY}

One of the most critical problems in patients with $\mathrm{AD}$ is their forgetting important information that should be well-known (agnosia), such as the name of children and spouses (Bennett, 2000) or well-somatized (apraxia). The donepezil treatment has been known to slightly reduce the frequency of memory-retrieval deficits in family relationships (Abe et al., 2007) suggests that $\mathrm{ACh}$ is necessary for recalling well-trained memory expressed frequently and almost automatically in daily living, and that the deficit of cholinergic functions leads to the above cognitive dysfunctions. On the other hand, cholinesterase inhibitors have been known to be less effective on late phase of $\mathrm{AD}$ patients, suggesting that cholinergic neurons are mostly depleted at that time. Therefore, our experimental protocol seems to imitate well the symptoms of late $\mathrm{AD}$ patients, and moreover can induce it reversibly. We believe that the reversibly-induced late $\mathrm{AD}$ animal model is useful for new drug screening and investigation of the neuronal mechanisms underlying amnesia. Thus, the present results deepen our understanding of the roles of ACh in memory 
functions and give clinical implications on diseases associated with ACh deficiency.

\section{AUTHOR CONTRIBUTIONS}

Shogo Soma and Satoshi Shimegi designed the research, Shogo Soma and Naofumi Suematsu collected the data and performed the analyses, and Shogo Soma and Satoshi Shimegi wrote the paper.

\section{ACKNOWLEDGMENTS}

We thank Drs. Takashi Kitsukawa, Hajime Sawai, and Tomomitsu Miyoshi for discussions and comments. We also thank Yuka Yamamoto for technical help, and Dr. Peter Karagiannis for improving the English of the manuscript. This work was supported by KAKENHI, 22500573, 25282216, and 25560302 to Satoshi Shimegi, Grant-in-Aid for JSPS Fellows to Shogo Soma.

\section{SUPPLEMENTARY MATERIAL}

The Supplementary Material for this article can be found online at: http://www.frontiersin.org/journal/10.3389/fnagi. 2014.00063/abstract

\section{Movie S1 | Rat performance of the 2AFC visual detection task under}

control condition. When a rat pulled the central-lever up, a grating patch appears on the right or left side of the display monitor. The animal was required to detect the stimulus and pull the corresponding choice-lever to obtain the reward through the lever.

\section{Movie S2 | Impairment of the retrieval of well-trained memory by}

scopolamine. The rat never manipulated the lever $0.5 \mathrm{~h}$ after administration of scopolamine at high concentrations $(0.30 \mathrm{mg} / \mathrm{kg})$.

Movie S3 | Recovery from the scopolamine-induced task impairment. At

$3 \mathrm{~h}$ after $0.30 \mathrm{mg} / \mathrm{kg}$ scopolamine administration, the rat set out to manipulate the lever but selected the choice-lever randomly, resulting in chance level of the task performance (see Figure $\mathbf{2 C}$ ).

\section{REFERENCES}

Abe, N., Ishii, H., Fujii, T., Ueno, A., Lee, E., Ishioka, T., et al. (2007). Selective impairment in the retrieval of family relationships in person identification: a case study of delusional misidentification. Neuropsychologia 45, 2902-2909. doi: 10.1016/j.neuropsychologia.2007.06.003

Bang, S. J., and Brown, T. H. (2009). Muscarinic receptors in perirhinal cortex control trace conditioning. J. Neurosci. 29, 4346-4350. doi: 10.1523/jneurosci.006909.2009

Bartko, S. J., Vendrell, I., Saksida, L. M., and Bussey, T. J. (2011). A computerautomated touchscreen paired-associates learning (PAL) task for mice: impairments following administration of scopolamine or dicyclomine and improvements following donepezil. Psychopharmacology (Berl.) 214, 537-548. doi: 10.1007/s00213-010-2050-1

Bartus, R. T. (2000). On neurodegenerative diseases, models, and treatment strategies: lessons learned and lessons forgotten a generation following the cholinergic hypothesis. Exp. Neurol. 163, 495-529. doi: 10.1006/exnr.2000.7397

Bartus, R. T., Dean, R. L., Beer, B., and Lippa, A. S. (1982). The cholinergic hypothesis of geriatric memory dysfunction. Science 217, 408-414. doi: 10.1126/science.7046051

Bennett, D. A. (2000). Part II. Clinical diagnosis and course of Alzheimer's disease. Dis. Mon. 46, 666-686. doi: 10.1016/S0011-5029(00)90029-4

Brainard, D. H. (1997). The psychophysics toolbox. Spat. Vis. 10, 433-436. doi: 10.1163/156856897X00357

Bushnell, P. J., Oshiro, W. M., and Padnos, B. K. (1997). Detection of visual signals by rats: effects of chlordiazepoxide and cholinergic and adrenergic drugs on sustained attention. Psychopharmacology 134, 230-241. doi: $10.1007 /$ s002130050446
Chopin, P., and Briley, M. (1992). Effects of four non-cholinergic cognitive enhancers in comparison with tacrine and galanthamine on scopolamine-induced amnesia in rats. Psychopharmacology 106, 26-30. doi: 10.1007/BF02253584

Curran, H. V., Schifano, F., and Lader, M. (1991). Models of memory dysfunction? A comparison of the effects of scopolamine and lorazepam on memory, psychomotor performance and mood. Psychopharmacology 103, 83-90. doi: 10.1007/BF02244079

Dai, Y. S., Ambudkar, I. S., Horn, V. J., Yeh, C. K., Kousvelari, E. E., Wall, S. J., et al. (1991). Evidence that M3 muscarinic receptors in rat parotid gland couple to two second messenger systems. Am. J. Physiol. Cell Physiol. 261, C1063-C1073.

Dickinson, A. (1985). Actions and habits: the development of behavioural autonomy. Philos. Trans. R. Soc. Lond. B 308, 67-78. doi: 10.1098/rstb.1985.0010

Edwards, D. F., Deuel, R. K., Baum, C. M., and Morris, J. C. (1991). A quantitative analysis of apraxia in senile dementia of the Alzheimer type: stage-related differences in prevalence and type. Dement. Geriatr. Cogn. 2, 142-149. doi: $10.1159 / 000107189$

Goard, M., and Dan, Y. (2009). Basal forebrain activation enhances cortical coding of natural scenes. Nat. Neurosci. 12, 1444-1449. doi: 10.1038/nn.2402

Gold, P. E. (2003). Acetylcholine modulation of neural systems involved in learning and memory. Neurobiol. Learn. Mem. 80, 194-210. doi: 10.1016/j.nlm.2003.07.003

Hasegawa, I., Fukushima, T., Ihara, T., and Miyashita, Y. (1998). Callosal window between prefrontal cortices: cognitive interaction to retrieve long-term memory. Science 281, 814-818. doi: 10.1126/science.281.5378.814

Hodges, D. B. Jr., Lindner, M. D., Hogan, J. B., Jones, K. M., and Markus, E. J. (2009). Scopolamine induced deficits in a battery of rat cognitive tests: comparisons of sensitivity and specificity. Behav. Pharmacol. 20, 237-251. doi: 10.1097/FBP.0b013e32832c70f5

Hughes, R. N., Desmond, C. S., and Fisher, L. C. E. (2004). Room novelty, sex, scopolamine and their interactions as determinants of general activity and rearing, and light-dark preferences in rats. Behav. Process. 67, 173-181. doi: 10.1016/j.beproc.2004.03.021

Jones, D. N. C., and Higgins, G. A. (1995). Effect of scopolamine on visual attention in rats. Psychopharmacology 120, 142-149. doi: 10.1007/BF02246186

Kaneko, T., and Thompson, R. F. (1997). Disruption of trace conditioning of the nictitating membrane response in rabbits by central cholinergic blockade. Psychopharmacology 131, 161-166. doi: 10.1007/s002130050279

Kang, J. I., Groleau, M., Dotigny, F., Giguére, H., and Vaucher, E. (2013). Visual training paired with electrical stimulation of the basal forebrain improves orientation-selective visual acuity in the rat. Brain Struct. Funct. 218, 1-15. doi: 10.1007/s00429-013-0582-y

Kimura, R., Saiki, A., Fujiwara-Tsukamoto, Y., Ohkubo, F., Kitamura, K., Matsuzaki, M., et al. (2012). Reinforcing operandum: rapid and reliable learning of skilled forelimb movements by head-fixed rodents. J. Neurophysiol. 108 , 1781-1792. doi: 10.1152/jn.00356.2012

Klinkenberg, I., and Blokland, A. (2010). The validity of scopolamine as a pharmacological model for cognitive impairment: a review of animal behavioral studies. Neurosci. Biobehav. Rev. 34, 1307-1350. doi: 10.1016/j.neubiorev.2010. 04.001

Klinkenberg, I., and Blokland, A. (2011). A comparison of scopolamine and biperiden as a rodent model for cholinergic cognitive impairment Psychopharmacology 215, 549-566. doi: 10.1007/s00213-011-2171-1

Levey, A. I., Kitt, C. A., Simonds, W. F., Price, D. L., and Brann, M. R. (1991) Identification and localization of muscarinic acetylcholine receptor proteins in brain with subtype-specific antibodies. J. Neurosci. 11, 3218-3226.

Luft, A. R., and Buitrago, M. M. (2005). Stages of motor skill learning. Mol. Neurobiol. 32, 205-216. doi: 10.1385/MN:32:3:205

Marti Barros, D., Ramirez, M. R., Dos Reis, E. A., and Izquierdo, I. (2004). Participation of hippocampal nicotinic receptors in acquisition, consolidation and retrieval of memory for one trial inhibitory avoidance in rats. Neuroscience 126, 651-656. doi: 10.1016/j.neuroscience.2004.03.010

Miranda, M. I., and Bermudez-Rattoni, F. (1999). Reversible inactivation of the nucleus basalis magnocellularis induces disruption of cortical acetylcholine release and acquisition, but not retrieval, of aversive memories. Proc. Natl. Acad. Sci. U.S.A. 96, 6478-6482. doi: 10.1073/pnas.96.11.6478

Mirza, N. R., and Stolerman, I. P. (2000). The role of nicotinic and muscarinic acetylcholine receptors in attention. Psychopharmacology 148, 243-250. doi: $10.1007 / \mathrm{s} 002130050048$ 
Nail-Boucherie, K., Dourmap, N., Jaffard, R., and Costentin, J. (2000). Contextual fear conditioning is associated with an increase of acetylcholine release in the hippocampus of rat. Cogn. Brain Res. 9, 193-197. doi: 10.1016/S09266410(99)00058-0

Pang, M. H., Kim, N. S., Kim, I. H., Kim, H., Kim, H. T., and Choi, J. S. (2010). Cholinergic transmission in the dorsal hippocampus modulates trace but not delay fear conditioning. Neurobiol. Learn. Mem. 94, 206-213. doi: 10.1016/j.nlm.2010.05.008

Parikh, V., Kozak, R., Martinez, V., and Sarter, M. (2007). Prefrontal acetylcholine release controls cue detection on multiple timescales. Neuron 56, 141-154. doi: 10.1016/j.neuron.2007.08.025

Pelli, D. G. (1997). The VideoToolbox software for visual psychophysics: transforming numbers into movies. Spat. Vis. 10, 437-442. doi: $10.1163 / 156856897 X 00366$

Penfield, W. (1952). Memory mechanisms. AMA Arch. Neurol. Psychiatry 67, 178-198. doi: 10.1001/archneurpsyc.1952.02320140046005

Pepeu, G., and Giovannini, M. G. (2010). Cholinesterase inhibitors and memory. Chem. Biol. Interact. 187, 403-408. doi: 10.1016/j.cbi.2009.11.018

Phillips, J. M., Mcalonan, K., Robb, W. G. K., and Brown, V. J. (2000). Cholinergic neurotransmission influences covert orientation of visuospatial attention in the rat. Psychopharmacology 150, 112-116. doi: 10.1007/s002130000437

Piri, M., and Zarrindast, M. R. (2011). Nitric oxide in the ventral tegmental area is involved in retrieval of inhibitory avoidance memory by nicotine. Neuroscience 175, 154-161. doi: 10.1016/j.neuroscience.2010.11.059

Ramírez-Amaya, V., Escobar, M. L., Chao, V., and Bermúdez-Rattoni, F. (1999). Synaptogenesis of mossy fibers induced by spatial water maze overtraining. Hippocampus 9, 631-636. doi: 10.1002/(SICI)1098-1063(1999)9:6<631::AIDHIPO3 > 3.0.CO;2-3

Rogers, J. L., and Kesner, R. P. (2003). Cholinergic modulation of the hippocampus during encoding and retrieval. Neurobiol. Learn. Mem. 80, 332-342. doi: 10.1016/S1074-7427(03)00063-7

Saper, C. B. (1984). Organization of cerebral cortical afferent systems in the rat. II. Magnocellular basal nucleus. J. Comp. Neurol. 222, 313-342. doi: $10.1002 /$ cne. 902220302

Shiraishi, K., and Takayanagi, I. (1993). Subtype of muscarinic receptors mediating relaxation and contraction in the rat iris dilator smooth muscle. Gen. Pharmacol. 24, 139-142. doi: 10.1016/0306-3623(93)90024-R

Sipos, M. L., Burchnell, V., and Galbicka, G. (1999). Dose-response curves and time-course effects of selected anticholinergics on locomotor activity in rats. Psychopharmacology 147, 250-256. doi: 10.1007/s002130051164

Smythe, J. W., Murphy, D., Bhatnagar, S., Timothy, C., and Costall, B. (1996). Muscarinic antagonists are anxiogenic in rats tested in the black-white box. Pharmacol. Biochem. Behav. 54, 57-63. doi: 10.1016/0091-3057(95)02130-2

Soares, J. C. K., Fornari, R. V., and Oliveira, M. G. M. (2006). Role of muscarinic M1 receptors in inhibitory avoidance and contextual fear conditioning. Neurobiol. Learn. Mem. 86, 188-196. doi: 10.1016/j.nlm.2006.02.006

Soma, S., Shimegi, S., Suematsu, N., and Sato, H. (2013a). Cholinergic modulation of response gain in the rat primary visual cortex. Sci. Rep. 3, 1138. doi: $10.1038 /$ srep 01138
Soma, S., Shimegi, S., Suematsu, N., Tamura, H., and Sato, H. (2013b). Modulation-specific and laminar-dependent effects of acetylcholine on visual responses in the rat primary visual cortex. PLoS ONE 8:e68430. doi: 10.1371/journal.pone.0068430

Soma, S., Suematsu, N., and Shimegi, S. (2013c). Cholinesterase inhibitor, donepezil, improves visual contrast detectability in freely behaving rats. Behav. Brain Res. 256, 362-367. doi: 10.1016/j.bbr.2013.08.022

Takahata, K., Minami, A., Kusumoto, H., Shimazu, S., and Yoneda, F. (2005). Effects of selegiline alone or with donepezil on memory impairment in rats. Eur. J. Pharmacol. 518, 140-144. doi: 10.1016/j.ejphar.2005.06.024

Tsui, C. K. Y., and Dringenberg, H. C. (2013). Role of cholinergic-muscarinic receptors in visual discrimination performance of rats: importance of stimulus load. Behav. Brain Res. 238, 23-29. doi: 10.1016/j.bbr.2012. 10.005

Wallenstein, G. V., and Vago, D. R. (2001). Intrahippocampal scopolamine impairs both acquisition and consolidation of contextual fear conditioning. Neurobiol. Learn. Mem. 75, 245-252. doi: 10.1006/nlme.2001.4005

Whitehouse, P. J., Price, D. L., Clark, A. W., Coyle, J. T., and Delong, M. R. (1981). Alzheimer disease: evidence for selective loss of cholinergic neurons in the nucleus basalis. Ann. Neurol. 10, 122-126. doi: 10.1002/ana.4101 00203

Whitehouse, P. J., Price, D. L., Struble, R. G., Clark, A. W., Coyle, J. T., and Delon, M. R. (1982). Alzheimer's disease and senile dementia: loss of neurons in the basal forebrain. Science 215, 1237-1239. doi: 10.1126/science.7058341

Wise, L. E., Iredale, P. A., Stokes, R. J., and Lichtman, A. H. (2007). Combination of rimonabant and donepezil prolongs spatial memory duration. Neuropsychopharmacology 32, 1805-1812. doi: 10.1038/sj.npp.1301297

Yin, H. H., and Knowlton, B. J. (2006). The role of the basal ganglia in habit formation. Nat. Rev. Neurosci. 7, 464-476. doi: 10.1038/nrn1919

Zarrindast, M. R., Sadegh, M., and Shafaghi, B. (1996). Effects of nicotine on memory retrieval in mice. Eur. J. Pharmacol. 295, 1-6. doi: 10.1016/00142999(95)00628-1

Conflict of Interest Statement: The authors declare that the research was conducted in the absence of any commercial or financial relationships that could be construed as a potential conflict of interest.

Received: 03 February 2014; paper pending published: 11 March 2014; accepted: 23 March 2014; published online: 08 April 2014.

Citation: Soma S, Suematsu N and Shimegi S (2014) Blockade of muscarinic receptors impairs the retrieval of well-trained memory. Front. Aging Neurosci. 6:63. doi: 10.3389/fnagi.2014.00063

This article was submitted to the journal Frontiers in Aging Neuroscience.

Copyright (c) 2014 Soma, Suematsu and Shimegi. This is an open-access article distributed under the terms of the Creative Commons Attribution License (CC BY). The use, distribution or reproduction in other forums is permitted, provided the original author(s) or licensor are credited and that the original publication in this journal is cited, in accordance with accepted academic practice. No use, distribution or reproduction is permitted which does not comply with these terms. 